\title{
Sociologia como ponto de vista
}

Luiz Carlos Jackson

0 texto inaugural da sessão C lássicos da Sociologia Brasileira, "A sociologia no Brasil", de Antonio C andido, foi publicado pela primeira vez em 1959, naEnciclopédia D elta-Larousse (queteve várias edições nos anos de 1960)ㄱ. Resultou de uma encomenda feita por Fernando deA zevedo a seus assistentes na cadeira de Sociologia II, Antonio Candido e Florestan Fernandes², que ficaram responsáveis pela redação do item sobre sociologia3.

Balanço da experiência compartilhada com outros jovens cientistas sociais, que herdaram da primeira geração de professores brasileiros e estrangeiros o compromisso de construir as ciências sociais em São Paulo, o texto de Antonio Candido é também o último que escreveu como sociólogo ${ }^{4}$, ainda que possamos discordar que ele tenha deixado de sê-lo em algum momento de sua trajetória acadêmica.

É possível destacar em sua obra, entretanto, uma série de textos estritamente sociológicos publicados entre 1947 e 1959: "O pinião e classes sociais em Tietê" (Sociologia, São Paulo, 1947, IX (2): 97-112); "O nobre: contribuição para o seu estudo" (Sociologia, São Paulo, 1948, X (23): 140-155); "Sociologia: ensino e estudo" (Sociologia, São Paulo, setembro de 1949, XI (3): 275-289); "The brazilian family" (em T. Lynn Smith e Alexander $\mathrm{M}$ archant (orgs.), Brazil: Portraits of $\mathrm{H}$ alf a C ontinent, N ova York, The Dryden Press, 1951, pp. 291-312); “Euclides da Cunha, sociólogo" (0 Estado de S. Paulo, São Paulo, 13/12/1952, p. 5);
1. Todas as referências desta apresentação foram retiradasdaexcelentebibliografia deAntonio $C$ andido, organizada por ViniciusD antas (São Paulo, D uasCidades/Editora 34, 2002).

2. $N$ ão se sabe em que ano foi feito o convite. Seposterior a 1954, Florestan estava à frente da cadeira deSociologial.

3. Incluído em sessão sobreas ciências sociais. Fernando de Azevedo escreveu uma introdução. 0 artigo deFlorestan trata do objeto, das divisões edo desenvolvimento histórico da sociologianaEuropa e nosEstados U nidos. 
4. Antonio C andido foi professor assistente na cadeiradeSociologiall, naFFCL-USP, dirigida por Fernando deAzevedo, de 1942 a 1958. D e 1958 a 1960 , lecionou Literatura Brasileira na Faculdade deFilosofia, Ciências eLetras deAssis. Assumiu acadera de TeoriaLiteráriae Literatura Comparada, na FFCL-U SP, em dezembro de 1960.

5. D o qual constam, sobretudo, "Literatura e cultura de 1900 a 1945", em Literatura e sociedade: estudosdeteoria e história literária (São Paulo, Companhia Editora N acional, 1965, 230 pp.); "O significado de Raízesdo Brasil", em Sérgio Buarque de H olanda, Raízesdo Brasil (5 ed., Rio de Janeiro, J oséO lympio, 1969, pp. XIX-XXX) e"Radicalismos", em Váriosescritos, 3 ed. revistaeampliada, São Paulo, D uas Cidades, 1995, 358 pp.
"Contribuição ao estudo de problemas do ensino rural" (em J. Q uerino Ribeiro, Pequenos estudos sobre grandes problemas educacionais: alguns as pectos do ponto de vista da administração escolar, São Paulo, 1952, pp. 1723 [tese apresentada ao IV C ongresso N ormalista de Educação Rural, em São Carlos, em outubro de 1951]); "A estrutura da escola: contribuição sociológica aos cursos especializados de administração escolar" (C aderno n. 5, São Paulo, FFCL da U SP, 1953, 33 pp.); "A vida familial do caipira” (Sociologia, São Paulo, 1954, XVI (4): 341-367); "Informação sobre a sociologia em São Paulo" (0 Estado de S. Paulo, São Paulo, 25/1/1954, p. 135 [número comemorativo ao IV Centenário, 1954]); "L'état actuel et les problèmes les plus importants des études sur les sociétés rurales du Brésil" (Anais do XXXI Congresso Internacional de Americanistas [em São Paulo, de 23 a 28/08/1954], v. I, São Paulo, Anhembi, 1955, pp. 321-332); "O papel do estudo sociológico da escola na sociologia educacional" (Anais do I Congresso Brasileiro de Sociologia, São Paulo, Sociedade Brasileira de Sociologia, 1955, pp. 117-130); "Possíveis raízes indígenas de uma dança popular" (Revista de Antropologia, São Paulo, junho de 1956, IV (1):1-24); "A sociologia no Brasil" (Enciclopédia D elta-Larousse, Rio de Janeiro, D elta S.A., 1959, pp. 2216-2232).

Infelizmente dispersos e de difícil acesso, constituem, juntamente com O sparcei ros do rio B onito: estudo sobre o cai pi ra paulista ea transformação dos seus mei os de vida (Rio de Janeiro, José O lympio, 1964, 239 pp.), a expressão de sua atuação como professor assistente de Sociologia na FFCL-USP nas décadas de 1940 e 1950. D eve-se notar, ainda, intervalo significativo demarcado pela última de suas "N otas de crítica literária" (27/2/1947), publicadas então no D iário de São Paulo, e o primeiro texto (sobre Guimarães Rosa, em 6/10/1956) publicado no Suplemento Literário de 0 Estado de S. Paulo. N ão há exagero na afirmação de que, nesse período, Antonio Candido foi, em primeiro lugar, sociólogo. Sua opção posterior pela crítica literária não pode ser compreendida sem que se considerem as perspectivas teóricas adquiridas nas ciências sociais.

Esse afastamento dos jornais permitiu finalizar também A formação da literatura brasileira (1959). C entrada em nossa formação literária, a obraprima de Antonio Candido é o ponto de referência para um conjunto de textos que avalia o sentido da experiência intelectual brasileira ${ }^{5}$, no qual se inscreve "A sociologia no Brasil". D uas grandesteses norteiam esse percurso, a primeira deriva da definição de literatura como sistema e, portanto, como representação coletiva. A segunda afirma sua precedência na construção de 
nossa identidade como nação em relação a outras formas de produção intelectual e artística.

$\mathrm{N}$ esse sentido, tanto a crítica da cultura como a sociologia deveriam constituir-se como resultantes dessa experiência histórica, decisiva para a conformação de certo estilo intelectual, marcado pelo rigor científico, mas também por liberdade expressiva. Este é, salvo engano, o ponto de vista sociológico que o autor defende vigorosa e discretamente, em meio às disputas e tensões que caracterizaram as décadas de institucionalização das ciências sociais em São Paulo.

Luiz C arlos Jackson é professor do D epartamento deSociologia da FFLCH -USP. E-mail: ljackson@usp.br. 